\title{
The ergonomic impact of agencies in the dynamic system of interpreting provision An ethnographic study of backstage influences on interpreter performance
}

\author{
Jiqing Dong and Graham H. Turner \\ Heriot-Watt University
}

\begin{abstract}
Interpreters are part of a complex system involving multiple human and technological agents, some of which are aggregated into the form of interpreting agencies. Interpreting is shaped by the ergonomics of the agency as well as by those of the courtroom, hospital or conference centre. The changing British economic climate and contractualism across the public services have brought the role of agencies to the fore. Drawing upon ethnographic data, the paper explicitly links the effect of agency management to practices on the ground and investigates the ergonomic barriers perceived by interpreters. We identify a set of organisational imperatives for recruitment, work allocation, professional ethics and collaborative working. As a key information interface, agencies do not always interact effectively with interpreters or consider their own ergonomic impact. We conclude that there is a need for more research on agencies as workplaces and employers of interpreters in the community.
\end{abstract}

Keywords: public service interpreting; interpreting agencies; ergonomics; work process; professionalisation.

\section{Public service interpreting in the UK: Professionalisation from above}

Recent decades have witnessed growing demands from professional bodies for re-landscaping the field of public service interpreting (PSI) in the UK (Townsley 2007). High-level efforts to regulate the professions abound, including the launches of the Diploma in Public Service Interpreting (DPSI) in 1991 and the National Register of Public Service Interpreters (NRPSI) in 1994, plus the recent success of legislative endeavours (e.g., EU directives 2010/64) in promoting the classic pathway towards securing occupational autonomy. However, paradoxical to the 
seemingly promising future of PSI's ongoing professionalisation (Larson 1977; Macdonald 1995) is the unglamorous nature of everyday interpreting, characterised by low prestige (Pöchhacker 2004), cheap labour (Mikkelson 1996), ad-hoc provision (Hale 2007) and other discouraging components. This sharp contrast is likely to trigger disruption in the efficacy of frameworks for interpreters' selfregulation.

In fact, in contrast to the enthusiasm for top-down restructuring, interpreters increasingly find their status questioned by policy-makers. The reality of frontline interpreting has not been substantially changed by regulatory intervention. This can partly be explained by the introduction of contracted agencies - characteristic of neo-liberalism, which favours flexible specialisation, blurred boundaries and centralised management control (Freidson 2001) - into the PSI sector. The pursuit of higher quality service in the PSI field has little to do with respect for knowledge or a shared 'service ethic' (Wilensky 1964) shaped through years of professional training. Rather, it comes as a result of the bureaucratic measurement and external monitoring, which force interpreters to behave in a manner considered professional. This professionalisation process of PSI is therefore initiated "from above" rather than "from within" (Evetts 2011), signalling a shift of work sovereignty from individual interpreters to the organisational (agency) managers. The dynamic system of interpreting provision often pivots on the competence of agencies in interpreter selection, job allocation and communication with public sector clients. Their backstage influences on interpreters performance can no longer be underestimated when PSI is arguably becoming a member of the chybrid professions' (Noordegraaf 2007; Colley and Guéry 2015) - a cluster of occupations (e.g., homecare workers, paralegals, midwives) in the public sphere that merely take on the look of professions without having actual jurisdictional control over practice (Evetts 2011).

Current socio-political changes set the scene for a re-examination of the contemporary role of agencies in organising the work of interpreting professionals. Whilst the interpreter's workplace is often construed as "that space in which communication is mediated by interpreting", every practitioner knows that what happens backstage is in fact critical to delivery of frontline services. The work involved in the provision of interpreting is therefore shaped by the ergonomics of the agency as well as by those of the courtroom, hospital or conference centre. Our overarching aim in this paper is thus to appraise the intended compatibility between interpreters and their work systems, accounting for the managerial and regulatory work undertaken by agencies, and to understand the impact of these relationships on the working lives of interpreters and the profession at large. Pivotal to this tripartite relation between the interpreter, the organisation (agency) and the profession is the management that propels the PSI work system. Accordingly, 
our research objective necessarily involves identifying the organisational and managerial tasks that regulate the work, so that a rational evaluation of their impact on interpreting practice can be implemented in future work. This leads to the first question to be addressed: To what extent are human factors incorporated in the organisational design and management of PSI practice?

The second objective is to explore the ergonomic effectiveness (see our explanation of 'cognitive ergonomics' below) of the measures implemented, focusing on the experiences of human operators who perform the work tasks. To that end, we are particularly keen to know: what are the ergonomic concerns that remain unaddressed in practice? An ergonomic analysis of the work process is employed to understand the importance of maintaining compatibility between organisational principles and the needs of human operators. Specifically, we build upon earlier findings (Dong and Napier 2016) and further explore ergonomic issues emerging from an interpreting agency case study. Through a qualitative thematic analysis (Hale and Napier 2013) of observational data and semi-structured interviews, the viewpoints of managers and interpreters regarding work process issues are compared in order to reveal hitherto under-appreciated aspects of the psychogeographical environments within which PSI practitioners operate.

The following section reviews the extant research on agencies as workplaces and the employment status of interpreters. We then identify and discuss, in the light of our data, the research gaps where an ergonomic perspective can contribute. We conclude by stating how our study augments understanding of the work and wellbeing of interpreters.

\section{Interpreting agencies: Beyond the "third client"}

It is hard to get to grips with agency-interpreter relationships without attending to the emergence of managerialism and contractualism in British social and welfare professions since the 1980s (Flynn 1990). In this context, agencies arise as a result of reduced expenditure on public service provision and political reliance on a free market that favours flexible labour and 'lean' employment relationships (Purcell, Purcell, and Tailby 2004). As a vital part of contemporary workplace, many agencies do not merely act as neutral go-betweens but exercise various modes of control over the non-standard workforce (Gossett 2006). While the organisational modes of agencies vary, it is their role in managing contingent workforces that has hitherto appealed to researchers (King, Burke, and Pemberton. 2005; Hoque and Kirkpatrick 2008; Carey 2013). A major problem is that agency personnel are often hired in a selling capacity against a sales-oriented work culture. They often "have an inferior knowledge of the task environment in which candidates will be 
required to work" (King et al. 2005, 987), restricting the chance to match a satisfactory person to the task. Agency workers typically cover the full spectrum from highly-skilled free agents at one end to low-valued, easily replaceable labour at the other (Kunda, Barley, and Evans 2002). The latter are often faced with undesirable work conditions and limited professional support (Kirkpatrick and Hoque 2006).

While British PSI work may seem to epitomise flexible employment in many ways, the interactions between PSIs and agencies remain under-researched (cf. Ozolins 2007). Scant examination has been dedicated to the specifics of managerial activities taking place within agencies, though the scandals of outsourcing legal interpreting services in the Criminal Justice System spurred huge anger from many practitioners (PI4J 2012). In the wider literature, accounts of the structural changes generated by changing patterns of employment tend to be merely summative. In Australia (Ozolins 2000) and Sweden (Norström, Gustafsson, and Fioretos 2011), as well as in Scotland (Pérez et al. 2006), interpreting provision is predominantly delivered by freelancers and rarely by permanent staff employed either by agencies or directly by the authorities, making the interpreters' situation in the international labour market highly insecure. The Swedish case study (Norström, Fioretos, and Gustafsson 2012) on the working conditions of community interpreters shows that professionalism was undermined by worsening salary structures, low social status and poor employment support. In particular, the authors point out that the deregulation of the market leads to competition between many agencies, forcing down prices and compromising quality. No public supervision is exercised to monitor their management, nor is there any guarantee that they will send qualified or authorised professionals to deliver services. On the other hand, interpreters in the Swedish study report that they are rarely informed of assignment details by agency representatives and are thus unable to be emotionally prepared for potential challenges. The work process can be further complicated by the convoluted layers of stakeholders nested in the system. Harrington (1997) identified some management forms adopted by sign language interpreting providers, ranging from agencies funded by local authorities on a corporate basis, to those contracted by responsible authorities such as social services departments. Yet uncertainty remains as to how effectively multiple parties' expectations are communicated via relevant channels of information to the point of service.

Discussion of the employment status of interpreters is equally noteworthy. Harrington (1997) compared the working conditions of freelance and salaried interpreters. Given the two co-existing working modes, he asserted that agencies, in order to continue employing qualified interpreters, should formulate equivalent policies for both part-time and full-time practitioners. One particular concern was that managers did not allow interpreters to comment on inappropriate assignments and working conditions via a formal grievance procedure. Most relevantly, 
Ozolins (2007) pointed out that many self-employed PSIs fail to recognise that agencies are actually their 'third client' - besides the two main parties (i.e., the service providers and users) in common interpreting encounters. Agencies are, however, not just clients of interpreters: the inter-dependence between the two is much more complex than a client-provider relationship would suggest. We therefore take the view that an investigation into how agencies act beyond the perceived clientele role is necessary. There is an ongoing tension between agencies' requirements and interpreters' autonomous decision-making. Understandings of professionalism sometimes diverge and managerial priorities may not always coincide with the interests of interpreters. This may, in part, be due to an unequal distribution of power between the parties. Given agencies' exclusive access (under the procurement mechanisms currently widespread in Britain) to public sector clients, and variations in management competence, it is hard to imagine that individual interpreters can actually respond to all three 'clients' in the same fashion.

In sum, two major gaps in the study of the agency-interpreter relationship are identified. On the one hand, the scarce research so far has only implicitly touched upon some dimensions of working conditions as experienced by interpreters. Agency-related factors that may prevent interpreters from functioning effectively at work have been subject to little in-depth investigation: much of what has been claimed proceeds from a weak empirical base. Secondly, studies of the actual work process choreographed by interpreting agencies have, at best, been rudimentary. The effect of managerial control at the operational level is rarely linked explicitly to shop-floor practices. Concomitantly, mutual expectations of this 'cooperative pair' have rarely been contextualised or cross-examined. This calls for a systematic approach to examine the components of managerial practice in situ and to see how they impact upon the work process of interpreters.

\section{An ergonomic perspective: In search of the "fit"}

Ergonomics, also known as the analysis of 'human factors', is concerned with the understanding of interactions among humans with other elements of a socio-technical system (IEA 2000). Lying at the heart of the discipline is the enduring search for design methods and principles to optimise human well-being and overall system performance (Bridger 2003). This sets the agenda in practice for ergonomic professionals, who are particularly responsible for making the system (e.g., artefact, facility, group, organisation or society) compatible with the abilities, needs and limitations of people. In the organisational context, this means matching the work with the people, tools, environment, rewards and other artefacts in the system. We find this line of thought highly relevant to our inquiry in that agencies 
can be perceived as a layer of information interface nested in the complex system of PSI (Figure 1).

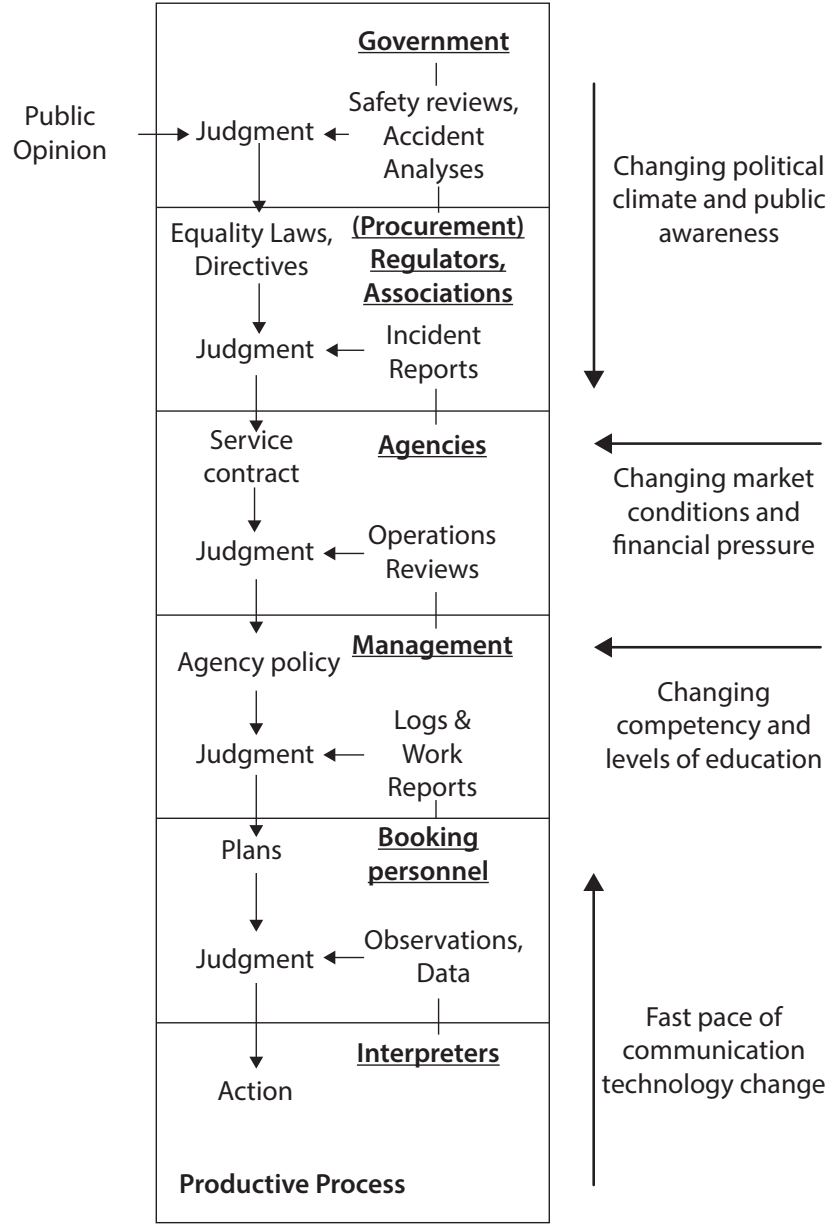

Figure 1. PSI workplace as an integrated part of the social-technical system (adapted

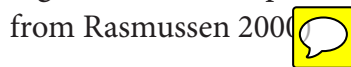

In this system, the agency, situated between the service requestors and suppliers, functions to dispatch suitable interpreters to meet the demands of clients. The core task of agencies, in light of the definition of ergonomics, is therefore to match the right interpreter with the right assignment at the right workplace, i.e., to enable a balanced compatibility or 'fit'. Of vital importance here is how information about the work - without which the ergonomic judgement of the fit can hardly be established - can be transmitted from the requestor via agencies to reach interpreters and vice versa. 
In this connection, organisational and cognitive ergonomics lay foundations for conceptualising management activities and interpreting practice respectively. Organisational ergonomics deals with the optimisation of organisational processes, including the social design of communication systems, interaction routines within working groups, organisational culture and quality management (IEA 2000). Ergonomists consider workers and their working environment as a highly interactive joint cognitive system (Hollnagel and Woods 2007) where determinants of performance failures should not be sought only in work. As stated by Curie and Hajjar (1987, 38, cited in Daniellou 2005, 414), "Each sub-system of activity is motivated by, and receives information from, what is happening in the other systems". This means the functionality of the agency sub-system would invariably affect the practice of interpreters. Accordingly, system ergonomics focuses on examining, accounting for, and enhancing the design of a system, and people's interactions with it, so that workers and the work can be organised to the best effect (Wilson 2014). Built on this rationale, we explore the extent to which human factors are incorporated in the organisational design and management of PSI practice.

Cognitive ergonomics, on the other hand, examines whether the solutions adopted suit the needs and characteristics of the users (IEA 2000). While its ultimate goal is also to improve work processes, the point of departure and the focus of cognitive ergonomics is the human being: it seeks to account for and respond to the implications of workers' mental processes - "how a person attends, remembers, makes decisions, communicates and acts in a particularly designed work system" (Cañas, Velichkovsky, and Velichkovsky 2011, 6). This necessitates an exploration of the workers' perceptions of constraining factors (e.g., communication barriers, health and safety, stress) that might affect their work performance. The essential task in cognitive ergonomics is trying to identify and understand the challenges posed by workplace processes and the adjustments workers implement in order to address them, thereby providing useful information in advance or fixing faulty systems to minimise concerns (Hollnagel 1997). We are therefore interested in those ergonomic concerns relating to agency-managed interpreters that remain unaddressed in practice.

We believe an ergonomic perspective with its focus on work process (organisational ergonomics), users' experiences (cognitive ergonomics) and their interaction is particularly applicable to our enquiry. This is in fact, not an entirely novel endeavour in our discipline. Colleagues in translation studies have already entered the workplace and reaped fruitful outcomes from work-process research. Studies focusing on the organisation and management of translation services (e.g., Gouadec 2007; Risku, Windhager, and Apfelthaler 2013; Kuznik and Verd 2010) renew attention to translation as work and employment. Ergonomics provides a 
framework to assess how translators use highly technologised tools. While interpreters have fewer technological barriers to overcome (or assistive devices to call upon, depending upon one's point of view), they do in many contexts work faceto-face with information interfaces of all shapes and sizes, with agencies being one of the most important interfaces. From this angle, it is safe to say that the ergonomic challenges that translators and interpreters are confronted with are not entirely the same but that their nature is revealingly comparable.

\section{Case and methods}

Fieldwork for this analysis was conducted under a generic case study strategy (Yin 2003). Commonly adopted by organisational researchers, this approach is regarded as useful in "understand[ing] how the organisational and environmental context is having an impact on or influencing social processes" (Hartley 2004, 325 ). We approached a national PSI service provider to negotiate entry into its business venue where day-to-day interpreting work is organised. ${ }^{1}$ The company Insight was "purposively sampled" (Patton 2002, 230) because it is one of the very few major agencies in the country run by managers with interpreting experience and has secured key indications of government approval including responsibility for certain high-stakes national training provision. ${ }^{2}$ These features suited our search for an information-rich example, where an independent research perspective would constitute a welcome learning opportunity for the business, thus bringing to life the concept of empowerment through knowledge exchange (Turner and Harrington 2000).

Data collection and analysis went hand in hand over a number of months in the field, but for the purpose of clarity, we present the process here in separate stages. Firstly, observational data (detailed description of the types of data used in Table 1) were collected over three months during which Dong was assigned to a dedicated workstation so that she could work relatively unobtrusively alongside agency colleagues. It was agreed that Dong could come to the office two to three days a week, depending on her availability. With the permission of the general manager, field notes were taken manually to record informal interaction, incidents, and the observation of work procedures, ranging from lunch breaks and in-car conversations to chance encounters on the stairs. Further descriptive accounts were noted down after the event, so that what was left out due to the strain

1. The research design had been pre-approved by our institutional ethics committee.

2. Insight is a pseudonym. 
of keeping pace with the ongoing communication could be filled in, in a timely manner. On occasions, including formal events such as board meetings, job interviews and training sessions, audio-recording was conducted with complementary notes. Additionally, a research journal was written to record the researcher's own reflections.

Table 1. Overview of data

\begin{tabular}{|c|c|c|c|}
\hline Data type & Quantity & Source & $\begin{array}{l}\text { Original data (intended) } \\
\text { audience }\end{array}$ \\
\hline Questionnaire & 22 questions & $\begin{array}{l}25 \text { interpreters who newly reg- } \\
\text { istered with Insight attending } \\
\text { the induction session at Insight. }\end{array}$ & Analysis for the study. \\
\hline $\begin{array}{l}\text { Field notes (ob- } \\
\text { servational) }\end{array}$ & $\begin{array}{l}25,000 \text { words } \\
(250 \mathrm{hrs})\end{array}$ & $\begin{array}{l}\text { Conversation between staff; } \\
\text { comments on emerging inci- } \\
\text { dents; applicant screening and } \\
\text { recruitment process. }\end{array}$ & $\begin{array}{l}\text { Internal staff; job ap- } \\
\text { plicants; analysis for the } \\
\text { study. }\end{array}$ \\
\hline $\begin{array}{l}\text { Meeting min- } \\
\text { utes }\end{array}$ & 5,000 words & $\begin{array}{l}\text { One board meetings and train- } \\
\text { ing planning meetings. }\end{array}$ & $\begin{array}{l}\text { Meeting attendees (board } \\
\text { members and training } \\
\text { team). }\end{array}$ \\
\hline $\begin{array}{l}\text { Audio- } \\
\text { recording of the } \\
\text { induction }\end{array}$ & 4.5 hours & $\begin{array}{l}\text { Key-note speech and presenta- } \\
\text { tion slides. }\end{array}$ & $\begin{array}{l}\text { Interpreters who newly } \\
\text { registered with Insight. }\end{array}$ \\
\hline $\begin{array}{l}\text { Research jour- } \\
\text { nal }\end{array}$ & 3,000 words & $\begin{array}{l}\text { Reflective notes on participant } \\
\text { observation. }\end{array}$ & Analysis for the study. \\
\hline $\begin{array}{l}\text { In-house archi- } \\
\text { val data }\end{array}$ & 50 pages & $\begin{array}{l}\text { Email communications; corpo- } \\
\text { rate rules and norms. }\end{array}$ & Freelance interpreters. \\
\hline $\begin{array}{l}\text { Artefacts/ } \\
\text { websites }\end{array}$ & N/A & $\begin{array}{l}\text { Organisational logos, symbols } \\
\text { and information leaflets. }\end{array}$ & $\begin{array}{l}\text { Prospective interpreters; } \\
\text { stakeholders; general } \\
\text { public. }\end{array}$ \\
\hline $\begin{array}{l}\text { London PIJ } \\
\text { seminar }\end{array}$ & 4 hours & $\begin{array}{l}\text { Seminar discussion, remarks of } \\
\text { manager from Insight. }\end{array}$ & $\begin{array}{l}\text { NRPSI interpreter } \\
\text { representatives across the } \\
\text { country. }\end{array}$ \\
\hline
\end{tabular}

While a large amount of "naturally-occurring data" (Silverman 2006, 21) addressing managerial activities was made accessible owing to the advantage of participant observation, it was equally important to gather "research-provoked" data which would allow interpreters to give voice to their work experience with agencies and their perception of professionalisation policies (especially, when their voices are mostly unheard in the organisational discourse). Moreover, controversial issues emerging from the unobtrusive data could then be triangulated and further clarified by the parties concerned. For this reason, semi-structured interviews were 
conducted with five agency members and 15 freelance interpreters who take assignments not only from Insight but also from other agencies. The background of informants can be found in Tables 2 and 3. During the individual interviews, the protocol of "grand tour questions" followed by "mini-tour questions" (Spradley 1979, 86-88) was adopted. Examples of the questions we asked include: "How did you start to work as an interpreter?" and "Could you describe your understanding of professionalism?" The aim of such interviews is to "encourage informants to ramble on and on" and "offer almost unlimited opportunities for investigating smaller aspects of experience" (Spradley 1979, 86-88). These interviews, each of which lasted from 60-90 minutes, were digitally recorded, fully transcribed and thematically coded.

To make sense of the full data-set, a grounded-theoretic approach (Glaser and Strauss 1967) was adopted. We began by assembling all of the collected evidence into a single digitalised file. With the aid of N-Vivo 10 software, we then used open-coding to identify relevant concepts by scrutinising the document line-byline, and grouped them into first-order codes, seeking traces of the ergonomic considerations in the work processes and their precedents. ${ }^{3}$ Built on these elementary codes where terms and accounts are adequate at the level of meaning of the informants (Van Maanen 1983), axial coding was further performed to examine the relationships between and among the first-order codes, the results of which were later consolidated into higher-order themes. This iterative process of comparing analytical reasoning and interpretation with evolving categories continued until the empirical data failed to reveal new findings (Strauss and Corbin 1990).

As is shown in Table 2, interpreters were locally sampled from the company database taking into consideration the diversity of languages (European and Asian languages) and ethnic backgrounds, years of working experience (ranging from one to twenty years), qualifications and training records. As such, four management staff of Insight (Table 3 ) and the group of practising interpreters naturally form the two units of analysis for the case study, with each attending to specific issues but altogether generating a global picture of the complex demand-supply system of PSI. The following section reports the findings.

3. Information on using $\mathrm{N}$-Vivo can be found at: http://download.qsrinternational.com/ Document/NVivo10/NVivo10-Getting-Started-Guide.pdf. Accessed April 8, 2016. 


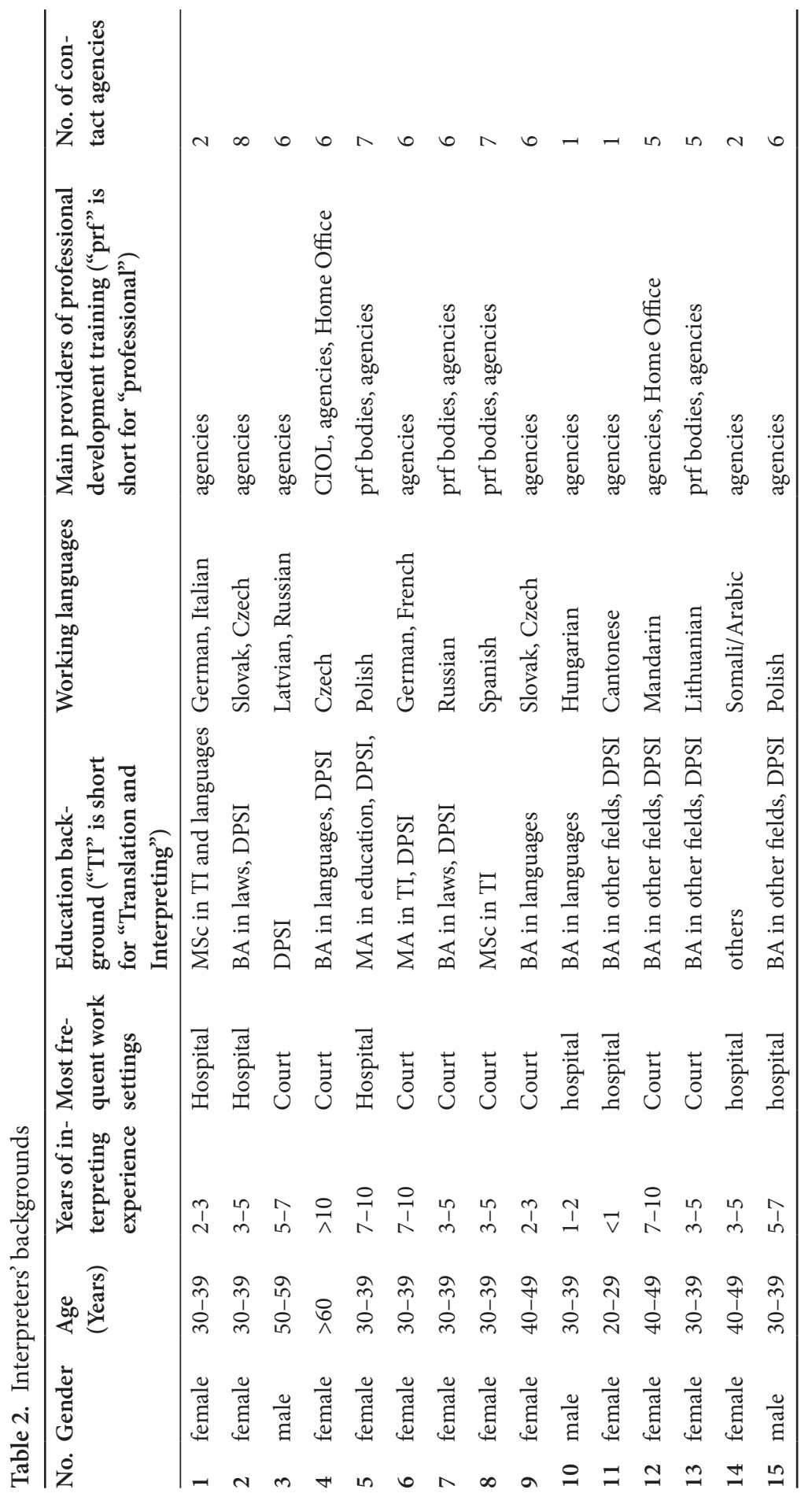


Table 3. The backgrounds of members of Insight

\begin{tabular}{|c|c|c|c|c|}
\hline No. Gender & $\begin{array}{l}\text { Age } \\
\text { (Years) }\end{array}$ & $\begin{array}{l}\text { Responsibilities } \\
\text { in the agency }\end{array}$ & $\begin{array}{l}\text { Years of interpret- } \\
\text { ing experience }\end{array}$ & Education background \\
\hline male & $30-39$ & Booking management & $2-3$ & MA in TI \\
\hline female & $30-39$ & $\begin{array}{l}\text { Booking management / } \\
\text { Training support }\end{array}$ & $2-3$ & $\mathrm{BA}$ in languages \\
\hline female & $30-39$ & Training officer & $5-7$ & BA in languages, DPSI \\
\hline female & $40-49$ & Executive director & $>10$ & DPSI, MBA \\
\hline
\end{tabular}

\section{Interpreting work management: Compact, complex and competitive}

Insight shares many traits of virtual enterprises in that it does not employ any in-house interpreters but has over 200 registered sessional workers at its disposal. Only two managers are permanent staff, with two self-employed interpreters contributing several hours a day in the office to deal with booking and other administrative work. Insight therefore has a compact management structure covering a wide range of responsibilities, which can be broadly categorised into human resources management (HRM), booking management, behavioural management and consultancy.

\subsection{HRM: "Picking the right frame of mind"}

HRM accounts for a large proportion of Insight's internal activities. Each interpreter with Insight has to go through a 1.5-hour assessment (sometimes longer) comprising interviews and interpreting assessments. This line of work is not handled as it would be at comparable mainstream interpreting agencies which collect candidate practitioners' CVs online and file copies of certificates, at best followed by a brief phone chat with the candidate. "No matter what they claim on the paper, we check. We don't assume", said one of the managers [A-mng-1]. ${ }^{4}$ For them, the interview is not only a channel to become acquainted with the applicants and scrutinise their command of relevant non-linguistic knowledge (e.g., professional ethics, work motivation and cultural inclusivity), but functions more as a test of the 'person-organisation fit'. In other words, those who are linguistically competent but do not suit the organisational culture are likely to be excluded. Of central

4. To mark the different sets of data, A refers to naturally-occurring data and B to elicited data: $\mathrm{mng}=$ manager int $=$ interpreter, doc $=$ documentary data. Individuals within each category are assigned a number. 
importance is that "people get into this profession with the right frame of mind" [A-director]. In the words of a manager who commented on a candidate:

What I find most difficult is when you have someone who is not too sure, a bit hesitant about certain meaning, and he thinks that it is ok or actually better than someone who says the complete wrong thing - that is a very dangerous act! [A-mng-2]

Such remarks point to the agency's preference for those who are honest in revealing the complexity of an interpreter's decision-making or show no trace of overassertiveness. Often, candidates making a poor impression in this round appear to stand little chance of being selected, no matter how well they perform in the following assessment. The sequence of these two procedures also reflects Insight's intention to implement a set of organisationally-defined criteria in PSI practice. Language skills are tested through role plays in the three general settings of PSI - legal, medical, and local government - which models the DPSI exams. Most importantly, the kind of setting(s) at which a candidate excels will be noted down in his or her profile for booking purposes.

Informants described their assessment experiences as 'challenging', 'stressed' or 'surprising', since none of them had been checked by other agencies to such an extent. Indeed, there remains a tacit rule in the market that quantity supersedes quality - in other words, agencies build reputations simply by showing how much work they have undertaken for previous clients (number of assignments, number of languages used, size of the pool of practitioners hired to provide services, and so forth). When Insight was approached by a larger agency with the opportunity of collaborative provision, the director commented:

He said he gonna use the old ones in their book. It's not been updated for years. He doesn't even know if they [the interpreters] have changed job or still stay there but, they won't check...you know, these days no one would bother until the point we know we won the contract, that's how procurement drives. [A-director]

Such a situation has been verified by a few interpreters who "have never seen the face behind the phone every time they [agencies] call" [B-int-6]. One stated:

They found me from the Translator's Café and didn't ask me for anything before sending me to the job. Every time I spoke to a different person and I don't think they are keen on knowing me.

The above quotes allude to a view that some agencies thrive on tendering for and securing procurement contracts. The lack of investment and interest in this profession is seen as rendering HRM an unused practice in such agencies, and 'real' interpreters (i.e., educated, capable and available) a precarious occupational group. 
HRM is also exemplified in the extent of support that Insight gives to interpreters. Before each assignment, the administrative team will brief interpreters with contextualised information that can help to reduce the uncertainty of the workplace. Advice includes, for example, "if you don't see the solicitor, the police guarding at the door of the courtroom is usually your man. He's got a list of names to call" [A-mng-2], or "the nurse may ask you to stay in the ward but make sure you wear the blue disposable gown outside, just next to handrail" [A-mng-1]. In turn, interpreters find Insight colleagues extremely good at helping them to "learn the ropes of the job" [B-int-5]. They mostly feel that they are able to obtain suggestions that could not have come from elsewhere. In fact, the majority of the participants express their confusion at the procedural knowledge that comes to play in specific work settings. Yet such knowledge is "very hard to obtain from those who haven't done the job" [B-int-7]. Some participants convey their hesitation to call agencies with queries for fear of being labelled as incompetent or losing jobs: "I am a bit scared to tell them what I feel difficult about, because they might be judgy of me and nothing gonna be resolved anyway." [B-int-11]

To tackle the above, the director of Insight describes their strategy as a "nonagency approach", the rationale of which is explained thus:

I don't want a thousand names on our book. That's not the type of agency we are. We need to know every single person who is working for us and have some sort of relationship with us, and feel that they belong to us, somehow. [A-director]

\subsection{Booking management: "Travel time matters"}

Booking management is perhaps the most basic function of all interpreting agencies. Just as individual interpreters are salaried by assignments, agencies are rewarded by meeting each booking request from client organisations. One fundamental principle of booking is "dispatching the right person to the right place at the right time" [A-mng-1]. In reality, it is much more easily said than done. The first reason is that Insight's choice is largely limited by being the secondary supplier for many contracts, i.e., only offered work assignments that a primary contractor cannot satisfy. As most 'popular jobs' will go straight to the first-tier contractor, Insight is inevitably faced with what members call the "leftovers" - typically last-minute requests or at remote locations. As a result, booking becomes a more exacting task, as the chances of locating an available and qualified interpreter become smaller. Worse still, the 'law of the jungle' that applies in the market does not allow managers much time to hesitate: "Clients won't wait, and there are plenty of agencies will say yes if we can't cover” [A-mng-2]. 
It is perhaps for these two reasons that specific procedures are designed by Insight to minimise the chance of missing any offer of jobs. Operators are instructed to follow pre-set steps that "always secure an interpreter first and then immediately assure the client". The response time for each request is measured to underpin their corporate strength in "providing the fastest possible response to clients" and to "remind people to speed up" [A-director]. There are a number of factors affecting work allocation. Among others, being (un)able to drive and the distance to the workplace are frequently raised when booking interpreters:

We pay travel time, but do you drive? We think travel time matters because we don't want to charge our clients three-hours travel time if we can avoid it. So I think the job in [name] area would be nearer to you... [A-mng-2]

On other occasions, driving ability becomes a criterion even in the early selection process of trainees, as revealed in a conversation by two members:

A-mng-1: So she's studying Health [option] but she failed the main part of the exam [DPSI], only got a letter of credit.

A-mng-2: Yeah but she drives. That's great. And also she doesn't get a lot of jobs from others.

A-mng-1: Yeah. That's a plus, because we then won't only have you [who can] drive.

Informants also report that using Google Maps to measure their actual travel time is problematic: "I often end up spending more on waiting for the bus or stuck in traffic" [B-int-10]. Some claimed that underestimation of the travel time would make them feel their work was underappreciated: "I wouldn't have taken the job if I knew my travel is not properly paid. It took me three hours total on the way for only a 10-minute assignment" [B-int-3].

Effective matching of interpreters to assignments requires consideration of human variables as well as rapid calculation of the financial costs of hiring one practitioner or another. Insight meticulously classifies each interpreter's expertise in the entry assessment. Yet we found that the recorded strengths of a specific practitioner can easily go unnoticed amongst the list of practical matters that have to be weighed in the balance. These include the rareness of the language in the respective country, since DPSI qualifications are not readily available for all languages, and gender requirements imposed for the assignment (there being fewer male than female interpreters). The degree of urgency may also be a factor there may be insufficient time to get hold of the ideal person - as may transport costs and accessibility. It may be impossible to reschedule the appointment, even if this would improve the interpreting, which may mean that the event must go ahead whatever the quality of interpreting available. When all these factors come 
into play simultaneously for a particular appointment, making the best match can become impossible.

Interpreters can therefore feel pressure to cover the job, especially when the agents sound desperate. Some informants reveal that managers in Insight "can be a bit of pushy as well, but in a nice way" [B-int-13]. Over half of the interviewees indicate that it is not always straightforward to say 'no' to certain agencies. One was concerned about losing work: "they would remember the times I refuse the job and tend to phone me less afterwards" [B-int-9]. Others believe "some agencies would blacklist me if I don't do the job or ask them to pay more" [B-int-4].

In the case where the constraining factors are kept to the minimum, the key to reducing work uncertainty and performance errors lies in the amount and the quality of the information passed on to interpreters to prepare. As commented by the director:

Our clients tell us that they would like to share more details but they are also restricted by confidentiality. It takes time for them to understand our profession but we always ask them for more, or advise them at least [to] brief interpreters before the meeting. [A-director]

This point is strongly confirmed by interpreters, many of whom seem to have many years' familiarity with the unpredictability of the conversations they are expected to interpret between the primary participants:

I guess that's part of our job. I mean I can do whatever I can based on what I have at hand. If they are reluctant to share information, then they have to be responsible for my mistakes too. [B-int-7]

The above quote seems to indicate that the interpreters' code of ethics, which includes an adherence to confidentiality just as other professionals have, does not seem to be widely recognised (and perhaps trusted) by the public.

\subsection{Behavioural management: "If someone hands you a red packet..."}

To enhance performance at the actual place of the interpreting assignment, Insight's managers have designed a set of internal work rules. These rules bear strong corporate traits in that they are not always constituted as standard parts of the code of practice but in many ways create a procedure out of the behaviour of interpreters at work. It was found that there are more 'identity rules' designed to mark members' collective identity than 'security rules' that are mainly concerned with the safety of interpreters.

Typically, interpreters are required to follow the bespoke dress code to "represent Insight in a responsible manner" [A-mng-1]. In the words of the director: 
We are probably the only agency that insists on people's dressing to do interpreting, because we're trying to forge a professional image. We want to make sure the people sent out by us are presentable, not like, just rolling out of the bed.

[A-director]

Each interpreter is given a company badge on which an ID photo and his or her name is placed below Insight's trademark. Before an assignment starts, interpreters are obliged to recite the "Self-Introduction" text at the back of the badge, which starts with: "My name is ___ from Insight" and proceeds with a succinct explanation of the role of interpreters and key interpreting protocols. The purpose of that, as explained by one manager, is to "make this as a procedure" because "it's important to establish the boundary at the beginning" [A-mng-1].

The organisational imperative is also shown in managers' rule-based construal of interpreting ethics. Insight interpreters are often reminded to "maintain confidentiality at all times" and told that the failure to do so will be regarded as "breaching the code" [A-director]. Similarly, "being impartial" has been redirected to novice interpreters as "keep[ing] a professional distance from the clients" [A-int-4], which some feel obliged to do but struggle in practice to obey: "In my culture, if someone hands you a red packet in some occasions, you can't really refuse! It's very rude to say no" [A-int-12]. ${ }^{5}$

Hardly any formal measures against work environment hazards are in place, apart from a "home-visit protocol" note attached to the details of assignment sent to interpreters (Figure 2) [A-doc]:

\title{
Please call the tenant on $07 \longrightarrow$ confirm this appointment
}

\begin{abstract}
In line with the protocol for home visits, please wait outside for the official to arrive and enter the premises together, i.e. do not go into the client's home yourself. If the official has not arrived 5 minutes into the appt. please inform the office and we will find out what is happening. When the assignment is finished, please leave with the official and do not stay behind on your own.
\end{abstract}

You are required to read and comply with the following-

\section{Terms \& Conditions}

Figure 2. Screenshot of an email from the documentary data

But even the original intention for this message is not entirely related to the concerns of the security risks that interpreters might be exposed to. As explained by the director:

Someone went in with the family in the house, by the time the official arrived, they are there having a cup of tea. The official didn't like that. When the appointment

5. In China and other East Asian countries, a monetary gift wrapped up inside a red packet or an envelope may be given to mark a special occasion such as a wedding, graduation or the birth of a baby. 
finished, the interpreter stayed behind and finished the tea. Later we got a complaint for that. [A-director]

Not all participants are comfortable with such required practices. Concerns are sometimes raised when interpreters arrive earlier than the official at the respective premise:

I have never managed to arrive at the same time with the health visitor. When I'm waiting around a dodgy area, to be honest I feel a bit scared. I actually feel safer with the clients at home than standing outside. [B-int-7]

None of the interviewees mentioned any training to assess the risks of the workplace, nor have they ever been informed of the potential dangers posed by particular clients and places. Although they agreed that the health and safety measures are inadequate, they were not sure who to consider responsible for that:

We are self-employed so I guess we have to take care of ourselves. Besides, agencies are not necessarily reliable, if we are warned of danger, who gonna do their jobs? [B-int-15]

One police interpreter mentioned the danger of wearing their ID badge in the cell: "I'm not sure about this because those criminals can remember my name easily and our community is quite small" [B-int-2]. Company rules like this disregard the mental burden added to the interpreters at work and pose a threat to their security outside the workplace, thus compromising the characteristics and needs of the human operators - the central concern of cognitive ergonomics in the work system design.

\subsection{Consultancy}

Consultancy work tries to harness the extensive efforts of the stakeholders to improve working conditions of interpreters. This mainly consists of providing training and advice to two audiences: other local interpreting agencies and public sector bodies. In search of the substance of this kind of expert insight, we found one email especially illuminating in that it points out some common ergonomic barriers created by agencies (Figure 3) [A-doc]:

Key points that are highlighted are the omissions of client's age, ambiguous instruction of time and place, and unclear subject information. Such issues may appear to be trivial in the eyes of many booking operators, but matter substantially for interpreters' frontline performance. Through working with local agencies, managers believe that they can "raise standards on a national scale by subscribing their partners to a common set of standards" [A-mng-1]. 


\begin{abstract}
$\mathrm{Hi}$
A few minor things. They are not really a big issue at the moment but will be helpful in the long run. There is also one issue about the Service Level Agreement I want to bring up before your meeting later.

(1) Patient's age or DOB: it is useful for the interpreter to know roughly the age of the person they are interpreting for. For example, the patient may be a baby or young child so the likelihood is the interpreter will be interpreting for the parents instead. Having the DOB makes it easier for the hospital to identify the patient when the interpreter arrives. Sometimes wrong spelling of names or wrong department or something else may mean the interpreter/NHS staff cannot find the patient for whom the interpreter is booked for.
\end{abstract}

(2) Include day of the week before the date: I swear by this method to avoid getting the dates wrong. It doesn't take much to do but it is very effective.

(3) Use 24-hour clock: Again to minimise potential mistake in taking down the time.

(4) Subject/nature of the appointment: This is not always clear from the venue or department, I think it should be a separate piece of info. For example, a patient is going in for Day Surgery, this could be absolutely anything. It helps the interpreter to get to the right place, but doesn't help them to prepare for the assignment other than something general about day surgery.

Figure 3. Screenshot of an email from the documentary data

In doing so, Insight allows for sharing information and good practice. Their approach has been adopted by several other agencies and has penetrated into the daily practice of local interpreters. Two local councils have requested their support in recruiting interpreters and organising training. Also, in its engagement with national healthcare providers, Insight was entrusted to devise a collaborative working guideline clarifying the responsibilities of health service providers, patients with preferred communication other than spoken English and interpreting agencies. These indications underline the organisation's status among relevant partners.

\title{
6. Discussion
}

At the beginning of this paper, we referred to the sharp contrast between the growing number of regulatory frameworks and the deteriorating working conditions for interpreters. While it is outside the scope of this article to investigate the political motivation behind the professionalisation scheme, the fact that the agencies' professionalisation policies produce limited effects on front-line interpreting work makes clear that something is malfunctioning in the current institutional network-system of PSI. This assumption leads us to refocus on the ergonomics of interpreting agencies which not only shape the worker/work interaction, but also in many ways reconstruct the model of interpreting professionalism in practice for the entire occupational group. Centring on this overarching aim, we addressed the first research question about the extent to which human factors are incorporated 
in the organisational design by identifying a set of organisational imperatives for recruitment, work allocation, professional ethics and collaborative working. While some of the measures in place have presumably been introduced to enhance knowledge exchange and interprofessional communication, others were felt to have tightened managerial control above individual autonomy and even put interpreters' safety at risk. As to the second objective, i.e., identifying the ergonomic issues which remain obstructive in practice, the findings illuminate the impact of management measures upon interpreting practice and reflect practitioners' perceptions of workplace ergonomics. Specifically, interpreters drew attention to, among other things, the lack of information provided for the assignment, lack of training and support, incompatible reward, stress and anxiety arising from being found incompetent by the agency, safety hazards in the workplace, and conflicting identities. Significant aspects of these ergonomic factors are discussed further on.

The study identified a range of management activities taking place within Insight. Seen from the viewpoints of managers and interpreters, these attempts by and large underpin an improved organisational design that enables a better fit between interpreters and the specific work they are offered. Bridger $(2003,1)$ argues that a better human-machine/system interaction can be achieved by "designing in" a better interface to make the system more compatible with the task and the user. By this logic, the core "designing-in" mechanism that runs such compatibility tests in Insight is the HRM team, a managerial component commonly missing from mainstream agencies. For ergonomics, the human constitutes an integral part of the system and must be fully incorporated into the system design: "Human requirements are thus system requirements, rather than secondary considerations" (Bridger 2003, 3). However, we did not find that interpreters were treated in the same way as ergonomists might expect. Instead, agencies on the whole are still responding to the job demands in a rather shallow fashion, and often without an in-depth understanding of either the person supposedly being matched or of the work itself. This triggers debate on whether PSIs are essentially high-skilled knowledge workers or low-paid, blue-collar labourers who are only indulged in the illusion of professionalisation. Interpreters face similar ergonomic risks to those characterising precarious employment elsewhere in the workforce (e.g., call-centre staff), typically including limited access to work, little freedom to refuse inappropriate tasks and ineffective communication - see Quinlan and Bohle (2004). A robust recruitment process, such as that which is being rolled out by Insight, can possibly reduce some chaotic arrangements. It not only draws a clearer occupational boundary to prevent the employment of untrained, lay interpreters, but also filters out candidates who might be bilingually competent yet lack the intercultural mediation skills to manage co-construction processes (Turner 1995) and triadic interaction (Pöchhacker 2008). Moreover, through face-to-face 
interviews, practitioners' strengths and weaknesses can be identified and recorded for later-stage management.

Worth mentioning here are Insight members' efforts to acculturate new candidates. Their intention to shape the habits of interpreters and expect them to embody a certain organisational 'character' again indicates that an organisational template is taking shape to unify an otherwise diverse, flexible workforce. This resonates with their intention to humanise the work of interpreters, i.e., treat individual interpreters with more care and respect. As reinforced in the interviews, interpreters' human needs do not normally earn the attention of agencies (either because agencies are not motivated or lack expertise). Interpreters' social and collegial needs are largely unmet owing to the fragmented nature of the work. The communicative gaps between individual interpreters and agencies are thus widened, which is bound to deepen the incompatibility problem arising from lack of effective matching of practitioners to assignments.

Two key consequences emerge from the data here. Firstly, the procedural knowledge produced in the process of doing interpreting jobs cannot be properly circulated and codified. The "network of practice" (Barley and Kunda 2004, 271) that serves as the major channel of information exchange for itinerant workers is interrupted as agencies are imposing prohibitive rules. Secondly, interpreters hold a sense of distrust toward agencies, which are thought to control a pool of jobs but not necessarily to allocate them based on ergonomic rationality. The suspicion and fear of losing the job is thus likely to strain the occupational limits of interpreters while concurrently intensifying their anxiety and estrangement at work. The situation is worsened by dominant agencies operating under non-expert management with inadequate understanding of the work tasks - a common source of disorder for contingent employment relationships (Kunda et al. 2002). In this connection, Insight's HRM activities - in particular, the attention they pay to vetting and support - substantially ease the ergonomic tensions perplexing PSIs in addition to the challenges presented by the delivery of actual linguistic services.

This is, however, not to say that the actual task of matching practitioners to assignments is solely based on the capabilities of interpreters. Despite the fact that interpreters have been organised according to levels and areas of competence, the booking priorities in reality are often subject to change as a result of environmental constraints. While many participants attribute their deteriorating working conditions to the unethical conduct of agencies, the results reveal that even agencies such as Insight are still struggling to offer clients better treatment in practice. Suffice it to say here that the top-down contractualism prevalent in the British public sector is liable to reproduce the current ergonomic obstacles for PSIs. This perhaps accounts for the identified decisions made by the managers (e.g., travel time, last-minute requests) that sometimes tip the scales in favour of minimising 
costs rather than maximising compatibility between interpreter and assignment. The managerial imperatives (e.g., response-time monitoring and Google-Map checks) set in place can therefore be understood as ways to enhance workers' performance or, perhaps more convincingly, to exercise disciplinary power over professional discretion, the intention of which hardly does justice to the ergonomic needs of interpreters.

Apart from reflecting upon the innate limit and characteristics of human operators, what equally matters to the compatibility equation is the configuration of the workplace environment. In other words, the improvement of a system can also be done by designing-out factors in the workspace that degrade the interactions between human and the milieu (Bridger 2003). While this appears to be beyond the direct control of agencies, the quality of the information they co-produce with the client organisations shapes the professional efficacy of interpreters' work. Feedback from the participants indicates that the lack of industry consensus on what and how much information should be shared prior to work poses various ergonomic challenges to PSIs. The absence of pre-assignment detail prevents them from conducting full risk assessments; nor is it feasible to predict the physical, cognitive, and emotional difficulties arising from the variety of work settings, be they hospitals, prisons or private homes. The sparse infrastructure for reporting protection failures and managing interpreters' safety chimes with the research on broader categories of agency workers and precarious work (Aronsson 1999; Quinlan, Mayhew, and Bohle 2001). Here, we provide evidence of another vulnerable occupational group, PSIs, who work closely with the service providers on the ground but are left isolated from the work planning conversations happening backstage. Surrounded by market-oriented managerial rhetoric, hardly any constructive suggestions based on the actual ergonomic experiences of interpreters can directly feed into the work process design at the policy level. In our case, it is apparent that Insight's consultancy capacity benefits wider groups of interpreters. Certain problematic procedures (e.g., disregarding "patient's age or DOB" in Figure 3) that have been employed for years are brought to light owing to their collaborative working strategy with the stakeholders. As shown in one of the examples, agencies should be aware that the day of birth (DOB) of the client can be a piece of important information for interpreters. For example, in cases where the patient is a baby or young child, the interpreter may end up interpreting for the parents instead.

Previous research also reports that agency workers suffer from a number of ergonomic discomforts at work, such as mental stress, volatile work pace, irregular working hours, low pay, problematic job locations and workplace disorganisation (Underhill and Quinlan 2011; Quinlan, Bohle, and Rawlings-Way 2015). We confirm the presence of these factors in the provision of PSI services and identify 
issues that have not been discussed explicitly, including interpreters' conflicting identities and agencies' rule-based interpretation of ethics. The former creates a dilemma about the extent to which interpreters should follow the rules of agencies. Their self-employed status is overshadowed by the power of agencies - so much so that they no longer treat agencies as their clients (Ozolins 2007). Rather, they abide by the rules of wearing badges as if they are employed and thus representing their employers. This is even done at the expense of exposing their names to potentially threatening clients, or staying in an unsafe environment to keep their role 'neutral' (in the home-visit example).

Furthermore, regulating the practice of ethics by giving strict "dos and don'ts" to interpreters does not seem to relieve their decisional pressure at work. On the contrary, it has been argued that an over-proceduralisation of their work restricts interpreters' ability to think analytically and cope with the multifaceted challenges at work (Dean 2015) - the core component of any knowledge-based profession claiming jurisdiction by the body of inaccessible knowledge (Abbott 1988). Previous research (e.g., Tate and Turner 1997) has critically evaluated the rule-based understanding of interpreting ethics in practice. Our findings indicate that this trend is probably in part driven by the managerial zeal to standardise work procedures and tighten control over professionals' decision-making. From the perspective of ergonomics, this inevitably reduces interpreters' scope to adjust their work activities according to personal conditions such as fatigue, anxiety or the fear of the consequences of breaching a code of employment.

Through an ergonomic investigation of the work process of PSI in the UK, it thus becomes clearer why high-level professionalisation efforts have so far generated relatively little traction. We argue that this is fundamentally down to the power of the front-line organisations that are centrally involved in interpreting practices. Among others, agencies are particularly pivotal in formulating the workplace order and managing ergonomic challenges through working with service providers. Yet our study shows agencies' ambiguous role in advancing this cause, or even steering practising interpreters away from the broader social-technical systems of PSI. The evidence presented leads us to conclude that ergonomic problems are inherent in the current design of a PSI system comprising various organisational interfaces that intersect with interpreting practice. Given that the constraining factors are, in many ways, affecting the quality of situated interpreting activities, we contend that there is a need for research to extend the notion of interpreting workplace beyond the space where communication-mediation tasks are performed, to where interpreting services are planned, organised and managed. Further research should therefore explore the ergonomic experience of interpreters and describe the implications arising from this flexible mode of employment. 


\section{References}

Abbott, Andrew. 1988. The System of Professions: An Essay on the Division of Expert Labor. Chicago: University of Chicago Press.

Aronsson, Gunnar. 1999. "Contingent Workers and Health and Safety." Work, Employment and Society 13 (3): 439-459. doi: 10.1177/09500179922118024

Barley, Stephen R., and Gideon Kunda. 2004. Gurus, Hired Guns and Warm Bodies: Itinerant Experts in a Knowledge Economy. Princeton, NJ: Princeton University Press.

Bridger, Robert. 2003. Introduction to Ergonomics. New York: Taylor \& Francis.

Cañas, José J., Boris B. Velichkovsky, and Boris M. Velichkovsky. 2011. "Human Factors and Ergonomics." In IAAP Handbook of Applied Psychology, edited by Paul R. Martin, Fanny M. Cheung, Michael C. Knowles, Michael Kyrios, Lyn Littlefield, J. Bruce Overmier, and José M. Prieto, 316-337. Oxford: Wiley-Blackwell. doi: 10.1002/9781444395150.ch13

Carey, Malcolm. 2013. "The Last Resort? Similarities and Differences between Contingent 'Agency' Employment Practices in Social Work and Nursing." International Social Work 56(4): 482-495. doi: 10.1177/0020872811421621

Colley, Helen, and Frédérique Guéry. 2015. "Understanding New Hybrid Professions: Bourdieu, Illusio, and the Case of Public Service Interpreters." Cambridge Journal of Education 45 (1): 113-131. doi: 10.1080/0305764X.2014.991277

daniellou, François. 2005. "The French-Speaking Ergonomists' Approach to Work activity: Cross-Influences of Field Intervention and Conceptual Models." Theoretical Issues in Ergonomics Science 6 (5): 409-427. doi: 10.1080/14639220500078252

Dean, Robyn. 2015. Sign Language Interpreters' Ethical Discourse and Moral Reasoning Patterns. Doctoral Dissertation, Heriot-Watt University, Edinburgh.

Q2 g, Jiqing, and Jemina Napier. 2016. "Towards the Construction of Organisational Professionalism in Public Service Interpreting." In Intersect, Innovate, Interact, edited by Pauline Henry-Tierney, and Dinithi Karunanayake, CTIS Occasional Papers, Vol. 7. Manchester: University of Manchester Centre for Translation and Intercultural Studies.

Evetts, Julia. 2011. "A New Professionalism? Challenges and Opportunities." Current Sociology 59 (4): 406-422. doi: 10.1177/0011392111402585

Flynn, Norman. 1990. Public Sector Management. London: Harvestoer Wheatsheaf.

Freidson, Eliot. 2001. Professionalism: The Third Logic. London: Polity.

Glaser, Barney, and Anselm L. Strauss. 1967. The Discovery of Grounded Theory: Strategies for Qualitative Research. Chicago: Aldine.

Gossett, Loril. 2006. "Falling Between the Cracks. Control and Communication Challenges of a Temporary Workforce." Management Communication Quarterly 19 (3): 376-415. doi: 10.1177/0893318905280327

Gouadec, Daniel. 2007. Translation as a Profession. Amsterdam: John Benjamins. doi: $10.1075 / \mathrm{btl} .73$

Hale, Sandra. 2007. Community Interpreting. Basingstoke/New York: Palgrave Macmillan. doi: $10.1057 / 9780230593442$

Hale, Sandra, and Jemina Napier. 2013. Research Methods in Interpreting: A Practical Resource, London/New York: Bloomsbury.

Harrington, Frank. 1997. "Agencies, Interpreters and the Deaf Community: Working in Harmony?" Deaf Worlds 13 (3): 3-8. 
Hartley, Jean. 2004. "Case Study Research." In Essential Guide to Qualitative Methods in Organizational Research, edited by Catherine Cassell and Gillian Symon, 323-333. London: SAGE Publications. doi: 10.4135/9781446280119.n26

Hollnagel, Erik. 1997. “Cognitive Ergonomics: It's All in the Mind.” Ergonomics 40 (10): 11701182. doi: 10.1080/001401397187685

Hollnagel, Erik, and David Woods. 2007. Joint Cognitive Systems: Foundations of Cognitive Systems Engineering. New York: Taylor \& Francis.

Hoque, Kim, and Ian Kirkpatrick. 2008. "Making the Core Contingent: Professional Agency Work and its Consequences in UK Social Services." Public Administration 86 (2): 33144. doi: 10.1111/j.1467-9299.2007.00704.x

IEA. 2000. International Ergonomics Association: Triennial Report. Santa Monica, CA: IEA Press. King, Zella, Simon Burke, and Jim Pemberton. 2005. “The 'Bounded' Career: An Empirical Study of Human Capital, Career Mobility and Employment Outcomes in a Mediated Labour Market.” Human Relations 58(8): 981-1007. doi: 10.1177/0018726705058500

Kirkpatrick, Ian, and Kim Hoque. 2006. "A Retreat from Permanent Employment? Accounting for the Rise of Professional Agency Work in UK Public Services." Work, Employment and Society 20 (4): 649-666. doi: 10.1177/0950017006069806

Kunda, Gideon, Stephen R. Barley, and James A. Evans. 2002. "Why do contractors contract? The experience of highly skilled technical professionals in a contingent labour market." Industrial and Labour Relations Review 55 (2): 234-261. doi: 10.1177/001979390205500203

Kuznik, Anna, and Joan Miquel Verd. 2010. "Investigating Real Work Situations in Translation Agencies. Work Content and its Components." Hermes-Journal of Language and Communication Studies 44: 25-43.

Larson, Magali Sarfatti. 1977. The Rise of Professionalism: A Sociological Analysis. Berkeley, CA: University of California Press.

Macdonald, Keith. 1995. The Sociology of the Professions. London: SAGE Publications.

Mikkelson, Holly. 1996. "The Professionalization of Community Interpreting." Proceedings of the 37th Annual Conference of the American Translators Association, 77-89. Accessed April 4, 2013. http://works.bepress.com/holly_mikkelson/23.

Noordegraaf, Mirko. 2007. "From "Pure" to "Hybrid" Professionalism: Present Day Professionalism in Ambiguous Public Service Domains." Administration and Society 39 (6): 761-785. doi: 10.1177/0095399707304434

Norström, Eva, Kristina Gustafsson, and Ingrid Fioretos. 2011. Interpreters in Sweden: A Tool for Equal Rights? Lund University. Accessed March 18, 2016. http://www.enl.auth.gr/gramma/gramma11/Norstrom_Gustafsson_Fioretos.pdf.

Norström, Eva, Ingrid Fioretos, and Kristina Gustafsson. 2012. "Working Conditions of Community Interpreters in Sweden: Opportunities and Shortcomings." Interpreting 14 (2): 242-260. doi: 10.1075/intp.14.2.06nor

Ozolins, Uldis. 2000. "Communication Needs and Interpreting in Multilingual Settings: The International Spectrum of Response." In The Critical Link 2: Interpreters in the Community, edited by Roda P. Roberts, Silvana E. Carr, Diana Abraham, and Aideen Dufour, 21-34. Amsterdam: John Benjamins. doi: 10.1075/btl.31.040zo

Ozolins, Uldis. 2007. "The Interpreter's 'Third Client': Interpreters, Professionalism and Interpreting Agencies." In Critical Link 4: Professionalization of Interpreting in the Community, edited by Cecilia Wadensjö, Birgitta Englund Dimitrova, and Anna-Lena Nilsson, 121-134. Amsterdam: John Benjamins. doi: 10.1075/btl.70.140zo 
Patton, Michael. 2002. Qualitative Research and Evaluation Methods, 3rd ed. Thousand Oaks, CA: SAGE Publications.

Perez, Isabelle A., Christine W.L. Wilson, Catherine King, and Celine Pagnier. 2006. Translating, Interpreting and Communication Support: A Review of Provision in Public Services in Scotland, Edinburgh. Scottish Executive Social Research. Accessed April 4, 2016. http:// www.gov.scot/resource/doc/90506/0021781.pdf.

PI4J. 2012. Professional Interpreters for Justice-NUPIT Campaigns [Online], Accessed April 8, 2016. http://www.unitetheunion.org/how-we-help/list-of-sectors/community-youthworkers-and-not-for-profit/nupitnationalunionofprofessionalinterpretersandtranslators/ nupitcampaigns/professionalinterpretersforjustice/.

Pöchhacker, Franz. 2004. Introducing Interpreting Studies. London: Routledge.

Pöchhacker, Franz. 2008. "Interpreting as Mediation." In Crossing Borders in Community Interpreting: Definitions and Dilemmas, edited by Carmen Valero-Garcés and Anne Martin, 9-26. Amsterdam: John Benjamins. doi: 10.1075/btl.76.02poc

Purcell, John, Kate Purcell, and Stephanie Tailby. 2004. "Temporary Work Agencies: Here Today, Gone Tomorrow?” British Journal of Industrial Relations 42 (4): 705-725. doi: 10.1111/j.1467-8543.2004.00337.x

Quinlan, Michael, and Philip Bohle. 2004. "Contingent Work and Occupational Safety." In The Psychology of Workplace Safety, edited by Julian Barling and Michael R. Frone, 81-106. Washington, DC: American Psychological Association. doi: 10.1037/10662-005

Quinlan, Michael, Philip Bohle, and Olivia Rawlings-Way. 2015. "Health and Safety of Homecare Workers Engaged by Temporary Employment Agencies" The Journal of Industrial Relations 57 (1): 94-114. doi: 10.1177/0022185614541179

Quinlan, Michael, Clare Mayhew, and Philip Bohle. 2001. “The Global Expansion of Precarious Employment, Work Disorganisation and Occupational Health: A Review of Recent Research." International Journal of Health Services 31 (2): 335-414. doi: 10.2190/607H-TTVo-QCN6-YLT4

Rasmussen, Jen, 2000. "Human Factors in a Dynamic Information Society: Where Are We Heading?” Ergonomics 43 (7): 869-879. doi: 10.1080/001401300409071

Risku, Hanna, Florian Windhager, and Matthias Apfelthaler. 2013. "A Dynamic Network Model of Translatorial Cognition and Action." Translation Spaces 2 (1): 151-182. doi: 10.1075/ts.2.08ris

Silverman, David. 2006. Interpreting Qualitative Data: Methods for Analysing Talk, Text and Interaction, 3rd ed. London: SAGE publications.

Spradley, James. 1979. The Ethnographic Interview. New York: Holt, Rinehart and Winston.

Strauss, Anselm, and Juliet Corbin. 1990. Basics of Qualitative Research: Grounded Theory Procedures and Techniques. Newbury Park, CA: Sage Publications.

Tate, Granville, and Graham Turner. 1997. "The Code and the Culture: Sign Language Interpreting-in Search of the New Breed's Ethics.” Deaf Worlds 13: 27-34.

Townsley, Brooke. 2007. "Interpreting in the UK Community: Some Reflections on Public Service Interpreting in the UK." Language and Intercultural Communication 7 (2): 163170. doi: $10.2167 /$ laic 272.0

Turner, Graham. 1995. "The Bilingual, Bimodal Courtroom: A First Glance." Journal of Interpretation 7 (1): 3-34.

Turner, Graham, and Frank Harrington. 2000. Interpreting Interpreting: Studies \& Reflections on Sign Language Interpreting. Coleford, UK: Douglas McLean. 
Underhill, Elsa, and Michael Quinlan. 2011. "How Precarious Employment Affects Health and Safety at Work: The Case of Temporary Agency Workers." Industrial Relations 66(3): 397421. doi: 10.7202/1006345ar

Van Maanen, John. 1983. “The Fact and Fiction in Organizational Ethnography." In Qualitative Methodology, edited by John Van Maanen, 37-55. Beverly Hills, CA: SAGE publications.

Wilensky, Harold. 1964. “The Professionalization of Everyone?” American Journal of Sociology 70 (2):137-158. doi: 10.1086/223790

Wilson, John R. 2014. "Fundamentals of Systems Ergonomics/Human Factors." Applied Ergonomics 45: 5-13. doi: 10.1016/j.apergo.2013.03.021

Yin, Robert K. 2003. Case Study Research, Design and Methods, 3rd ed. Thousand Oaks, CA: Sage Publications.

\section{Authors' addresses}

Jiqing Dong

Centre for Translation \& Interpreting Studies

in Scotland

Department of Languages \& Intercultural

Studies

School of Management \& Languages

Edinburgh, Scotland EH14 4AS

Heriot-Watt University

jd199@hw.ac.uk
Professor Graham H. Turner

Centre for Translation \& Interpreting Studies in Scotland

Department of Languages \& Intercultural

Studies

School of Management \& Languages

Edinburgh, Scotland EH14 4AS

Heriot-Watt University

g.h.turner@hw.ac.uk

\section{Bionotes}

Jiqing Dong studied for her PhD at CTISS (2012-2016). After completing her Master Degree in Guangdong University of Foreign Studies in China, she was awarded a scholarship by China Scholarship Council (CSC) to undertake her $\mathrm{PhD}$, which investigates the work processes between interpreters and agencies in Scotland and how managerial-organisational power redefines the meaning of professionalism in public service interpreting. Her research interests focus on interpreter-mediated communication in primary legal and medical settings; translation as a cultural and political practice; and using action research to explore interpreting pedagogy.

Graham H. Turner joined the Department of Languages and Intercultural Studies as Professor and Director of the Centre for Translation \& Interpreting Studies in Scotland in October 2005. He has published widely, edited international journals in Deaf Studies and in Translation \& Interpreting Studies, and is a former elected Hon Secretary of the British Association for Applied Linguistics. Graham's research focuses on language in society, with special reference to interpreting studies and to British Sign Language (BSL). 